\title{
RANCANG BANGUN PENYEMPROT PESTISIDA UNTUK PERTANIAN PADI BERBASIS QUADCOPTER
}

\author{
Anton Yudhana, Miko Wardani \\ Program Studi Teknik Elektro, Fakultas Teknologi Industri, Universitas Ahmad Dahlan \\ Kampus III, Jln. Prof. Dr. Soepomo, S.H. Umbulharjo, Yogyakarta 55161 \\ e-mail: eyudhana@ee.ac.id, micowardani@gmail.com
}

\begin{abstract}
Quadcopter is the development of the helicopter it simply using the rotor. Quadcopter has more used the research objective which is into the agriculture field. Quadcopter can be used to conduct the land surveys, the remote sensing and other that present to be easly the agricultural activities for pest and fertilizer spraying. In the future, quadcopter will be feasible to utilize and develop efciently the technologies it can assisting the paddies farming. Hazardous pesticides do not expose into the skin directly, inhaled or the eyes. Accidents from the pesticides effect it by doing the farmers, and those used manual spray pumps. To minimize dissemination risks then this study designed the quadcopter remote control for spraying the pesticide liquids to the rice plants. the quadcopter type $X$ with the dimension of $650 \mathrm{~mm}$ made by Tarot it used in this research. The quadcopter has moving with four propeller and the size of $13 \times 5.5$ inch that mounted on the brush motor of 700KV. The quadcopter has two stages for take off position it by flight mode of GPS hold to spray the pesticide liquid and automatic flight mode using the mission planning software. The pesticide dissemination using the quadcopter has produced the better spraying when conducted in three meter of elevation by nozzle holder rate of $75 \%$.
\end{abstract}

Keywords: quadcopter; pesticide; nozzle holder; mission planner.

\begin{abstract}
Abstrak
Quadcopter adalah pengembangan dari helikopter yang hanya memiliki sebuah rotor. Quadcopter banyak menjadi objek penelitian salah satunya dalam bidang pertanian. Quadcopter dapat digunakan untuk melakukan survei lahan, pemantauan jarak jauh maupun lainnya untuk mempermudah aktivitas pertanian terutama untuk penyemprotan hama dan pemupukan. $\mathrm{Di}$ masa mendatang teknologi ini layak untuk dimanfaatkan dan dikembangkan guna membantu kegiatan pertanian yang tepat guna dan efisien. Pestisida berbahaya tidak boleh terkena kulit secara langsung, terhirup atau mengenai mata. Kecelakaan akibat pestisida dialami petani terutama yang menggunakan penyemprotan secara manual pump. Untuk meminimalisir resiko penyemprotan maka dirancang quadcopter remote control khusus untuk menyemprotkan cairan pestisida pada tanaman padi. Quadcopter yang digunakan pada penelitian ini adalah jenis quadccopter tipe $\mathrm{X}$ dengan dimensi $650 \mathrm{~mm}$ yang dibuat oleh tarot. Quadcopter bergerak menggunakan 4 buah baling-baling (propeller) dengan ukuran $13 \times 5,5$-inch yang dipasang pada motor brushless 700KV. Quadcopter pada saat penyiraman cairan pestisida melakukan take off menggunakan 2 cara, yaitu penyemprotan dengan mode terbang GPS-hold dan penyemprotan mode terbang secara otomatis diatur melalui Mission Planner software. Penyemprotan pestisida menggunakan quadcopter menghasilkan penyemprotan yang sempurna apabila penyemprotan dilakukan dengan ketinggian $3 \mathrm{~m}$ dengan menggunakan persentase nozzle holder $75 \%$.
\end{abstract}

Kata Kunci: quadcopter, pestisida; nozzle holder, mission planner. 


\section{Pendahuluan}

Dalam perkembangannya, quadcopter dapat digunakan sebagai kendaraan udara tanpa awak atau unmanned aerial vehicle (UAV). UAV adalah salah satu teknologi yang sedang mengalami perkembangan yang pesat dan memiliki potensi yang sangat besar, baik untuk keperluan militer maupun kepentingan sipil.

Dengan kemampuan yang dimiliki quadcopter, dapat juga difungsikan untuk penyemprotan hama dan pemupukan secara langsung dengan lebih tepat di lokasi yang terserang hama. Dengan kemampuan yang dimiliki quadcopter, dapat juga difungsikan untuk penyemprotan hama dan pemupukan secara langsung dengan lebih tepat di lokasi yang terserang hama [1].

Di bidang pertanian, penggunaan pestisida juga telah dirasakan manfaatnya yaitu untuk meningkatkan hasil produksi, akan tetapi hal ini akan membuat tingkat ketergantungan sangat tinggi terhadap pestisida. Pestisida tidak boleh terkena kulit secara langsung, terhirup atau mengenai mata manusia karena pestisida terkadung bahan kimia yang berbahaya. Kecelakaan akibat pestisida yang dialami seperti, pusing-pusing ketika sedang menyemprot maupun sesudahnya, atau muntah-muntah, mulas, mata berair, kulit terasa gatal-gatal dan menjadi luka, kejang-kejang, pingsan, dan tidak sedikit kasus berakhir dengan kematian [2]. Penyemprotan manual pump ini juga berpotensi merusak tanaman karena dalam proses penyemprotan banyak tanaman yang terinjak. Maka di perlukan inovasi untuk meminimalisir resiko untuk penyemprot dan tanaman itu sendiri. Dirancang remote control quadcopter khusus untuk menyiramkan cairan pada tanaman padi [11]. Alat ini memiliki banyak keunggulan antara lain, penyemprot tidak terkena pestisida karena jarak antara quadcopter dan pengendali cukup jauh, tanaman tidak terjadi kerusakan karena quadcopter tidak menginjak tanaman, waktu penyemprotan dengan menggunakan quadcopter dapat lebih singkat.

\section{Metode Penelitian}

Quadcopter yang digunakan pada penelitian ini adalah jenis quadccopter tipe $\mathrm{X}$ dengan dimensi $650 \mathrm{~mm}$ yang dibuat oleh Tarot. Quadcopter bergerak menggunakan 4 buah balingbaling (propeller) dengan ukuran $13 \times 5,5$-inch yang dipasang sedemikian rupa pada motor brushless 700KV. Adapun rancangan quadcopter disajikan pada Gambar 1.

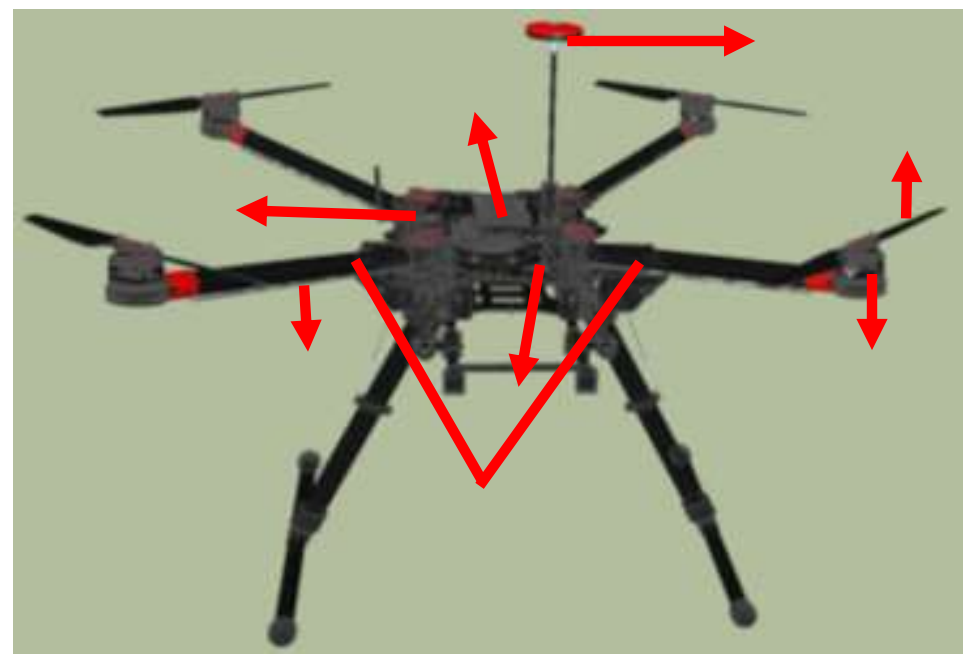

Gambar 1. Desain 3D quadcopter

Perancangan hardware quadcopter menggunakan software 3D google sketch up 2016. Dalam perancangan tersebut ada delapan bagian utama yang digunakan quadcopter, adapun penjelasan delapan bagian utama disajikan pada Tabel 1 . 
Tabel 1. Keterangan bagian utama quadcopter

\begin{tabular}{cc}
\hline Nomor & Keterangan \\
\hline 1 & GPS \\
2 & Flight controller \\
3 & Telemetry \\
4 & Motor brushless \\
5 & Propeller \\
6 & LED strip 5050 \\
7 & ESC \\
8 & Quadcopter frame \\
\hline
\end{tabular}

Perakitan quadcopter dengan spesifikasi yang telah dipilih dihasilkan prototype quadcopter yang disajikan pada Gambar 2.

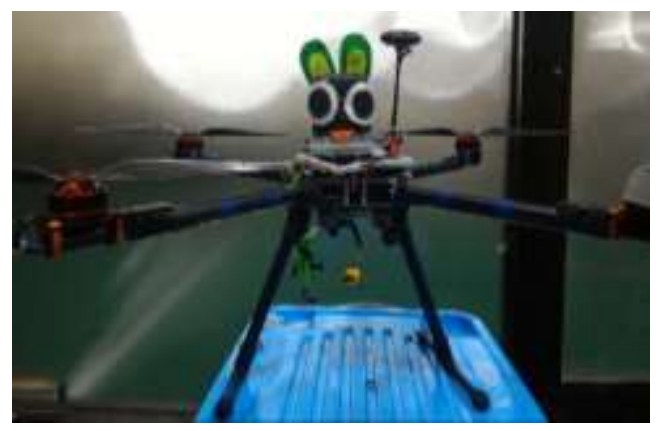

Gambar 2. Prototype quadcopter

Quadcopter tersebut membutuhkan spesifikasi yang tinggi dengan torsi yang besar karena digunakan untuk mengangkat alat penyemprot cairan pestisida. Quadcopter tersebut dapat mengangkat beban $1,5 \mathrm{Kg}$.

\subsection{Konfigurasi Hardware Water Pump}

Water pump adalah sebuah alat yang digunakan dalam menyemprotkan cairan pestisida pada penelitian ini. Pada konfigurasi hardware water pump terdapat beberapa komponen seperti yang disajikam pada Tabel 2 .

Tabel 2. Komponen konfigurasi hardware water pump

\begin{tabular}{cc}
\hline No & Komponen \\
\hline 1 & Jerigen 1 Liter \\
2 & Sensor water level \\
3 & Pneumatic air fitting \\
4 & Selang pneumatic \\
5 & Nozzle \\
6 & Motor DC (pump) 12 V \\
7 & Action Cam \\
8 & Rangkaian compact rc switch circuit \\
\hline
\end{tabular}

Komponen tersebut didesain menggunakan google sketch up, hasil dari desain tersebut disajikan pada Gambar 3. 

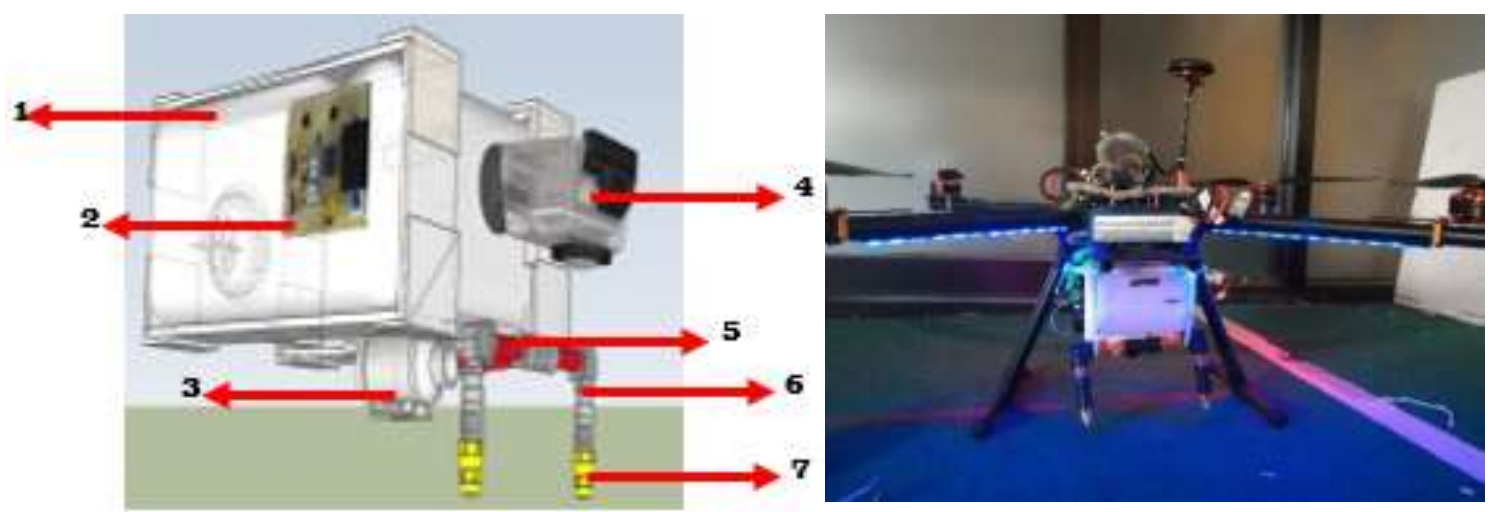

Gambar 3. Desain (a) 3D water pump, (b) prototype water pump terpasang pada quadcopter

Gambar 3 ada beberapa komponen yang digunakan dan ditunjukan pada Tabel 3.

Tabel 3. Keterangan nomor pada desain hardware water pump

\begin{tabular}{cc}
\hline Nomor & Keterangan \\
\hline 1 & Jerigen 1 Liter \\
2 & Rangkaian compact rc switch circuit \\
3 & Motor DC (pump) 12 V \\
4 & Action cam \\
5 & Selang pneumatic \\
6 & Pneumatic air fitting \\
7 & Nozzle \\
\hline
\end{tabular}

Dalam konfigurasi hardware water pump terdapat tambahan rangkaian sebagai penguat tegangan receiver transmitter $\mathrm{RC}$ untuk mengaktifkan dan mematikan water pump pada saat water pump akan menyemprotkan cairan pestisida. Rangkaian tersebut yaitu RC switch compact circuit dengan IC OP-AMP LM358. Rangkaian RC switch bisa digunakan untuk apa saja, seperti mengaktifakan indikator, menurunkan beban, merubah sinyal video, dan menggerakan landing gear. Keluaran RC switch ini dapat menyesuaikan dengan arus yang besar [3]. Dalam proses pembutan rangkaian diperlukan desain skematik dan layout PCB. Proteus 8 Profesional adalah perangkat lunat yang digunakan untuk mendesain skematik dan juga layout PCB. Adapun rangkaian yang dibuat yaitu skematik dan desain PCB RC switch compact circuit seperti pada Gambar 4.

Cara kerja dari rangkaian $\mathrm{RC}$ switch compact circuit yaitu, rangkaian rc switch akan aktif ketika mendapat tegangan sebesar 12 volt. Komponen utama pada rangkaian ini terletak pada IC OP-AMP LM 358. IC OP-AMP LM 358 memiliki 2 buah OP-AMP didalamnya. Masukan inverting OP-AMP 1 terhubung dengan pin receiver dan masukan inverting OP-AMP 2 terhubung dengan sensor water level. Saat masukan inverting dan non-inverting pada OP-AMP 1 terjadi perbedaan nilai maka keluaran OP-AMP1 akan mengeluarkan keluaran tegangan ke transistor NPN 1 yang befungsi untuk mencetuskan relay. Ketika relai dalam kondisi energized, relai akan mengaktifkan water pump yang terhubung dengan sumber tegangan 12 volt. Ketika input inverting dan non-inverting OP-AMP 2 terjadi perbedaan nilai maka output OP-AMP 2 akan mengeluarkan ouput tegangan ke transistor NPN 2 yang berfungsi untuk menghidupkan dan mematikan LED indikator water level. Kedua OP-AMP pada LM 358 terdapat masing-masing 1 buah variabel resistor yang berfungsi untuk mengubah-ubah kondisi masukan non-inverting pada OP-AMP, agar menghasilkan keluaran tegangan yang sesuai dengan yang diinginkan. 


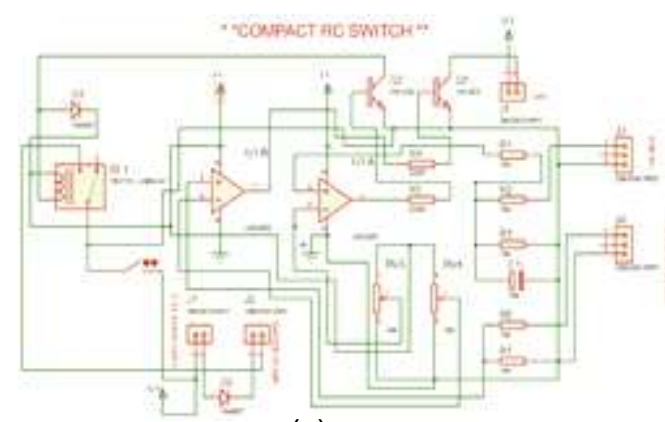

(a)

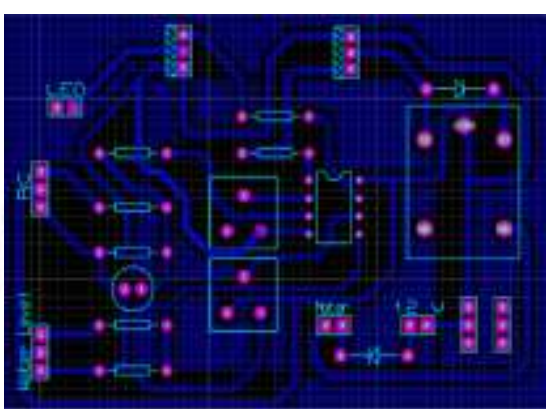

(b)

Gambar 4. Tampilan (a) skematik dan (b) PCB-RC switch compact

\subsection{Strategi Penyemprotan}

Ada dua metode penyemprotan yaitu dengan menggunakan GPS-hold dan waypoint, adapun penyiraman pestisida dengan take-off GPS-hold mode disajikan pada Gambar 5 dan waypoint disajikan pada Gambar 6.

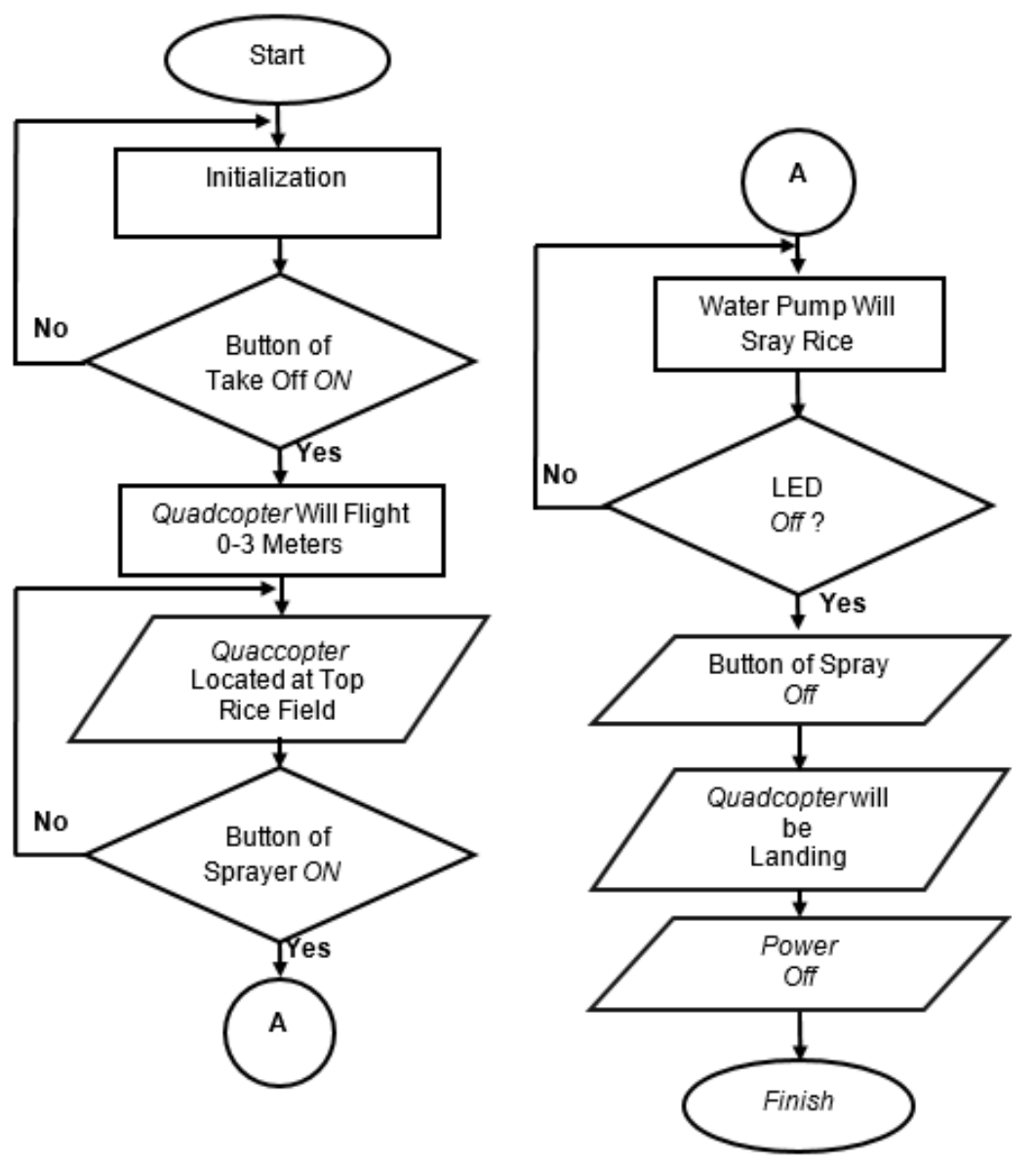

Gambar 5. Diagram alir penyemprotan menggunakan mode GPS-hold 

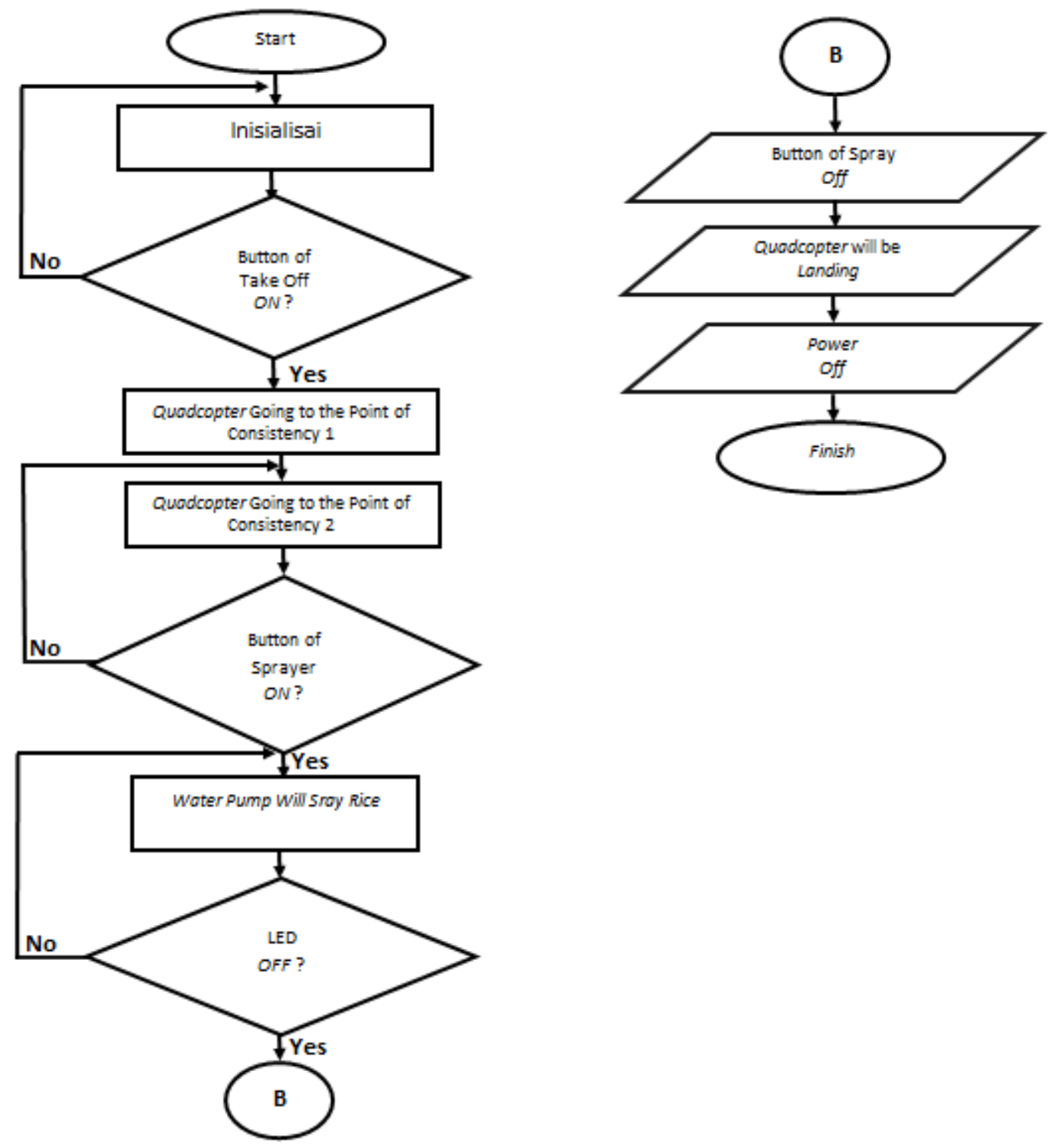

Gambar 6. Diagram alir penyemprotan dengan menggunakan waypoint mode

Proses awal yang dilakuan adalah membuat titik koordinat menggunakan software mission planner. Dengan menggunakan mode waypoint ini selain dapat membuat titik koordinat, juga dapat mengatur kecepatan dan ketinggian pada quadcopeter. Setelah titik koordinat sudah dibuat, pilot akan mengirim data ke flight controller dan kemudian mengaktifkan action camera. Untuk pengisian cairan pestisida sama seperti saat melakukan penerbangan dengan GPS-hold mode yaitu dengan menuangkan cairan pestida pada wadah yang terpasang antara landing gear quadcopter. Pada saat akan melakukan take-off dengan mode waypoint, pilot hanya mengaktifkan tombol throttle dan mengarahkan tombol throttle ke atas (up throttle). Quadcopter secara otomatis akan take-off dan mengarah pada titik koordinat yang sudah dibuat. Ketika quadcopter sudah berada di titik koordinat ke dua, pilot akan mengaktifkan tombol penyemprot pada remote control. Selanjutnya water-pump akan aktif dan menyemprotkan padi hingga indikator pada LED pada kondisi off yang menandakan pestisida habis. Setelah pilot mengetahui pestisida sudah habis berdasarkan keadaan indikator LED pada kondisi off, kemudian pilot mematikan tombol semprot. Dengan secara otomatis quadcopter akan melakukan landing pada titik koordinat yang sudah ditentukan. 


\section{Hasil dan Pembahasan}

Pengujian ini dilakukan cara memutarkan nozzle yang terletak pada ujung nozzle. Besar nilai prosentase pada ujung nozzle diketahui dari sebuah tanda yang terdapat pada ujung nozzle. Pengujian ini dilakukan dalam keadaan tidak take off dengan ketinggian $2 \mathrm{~m}$ dan $3 \mathrm{~m}$. Adapun hasil dari pengujian nozzle dengan ketinggian 2m dapat dilihat pada Gambar 7.

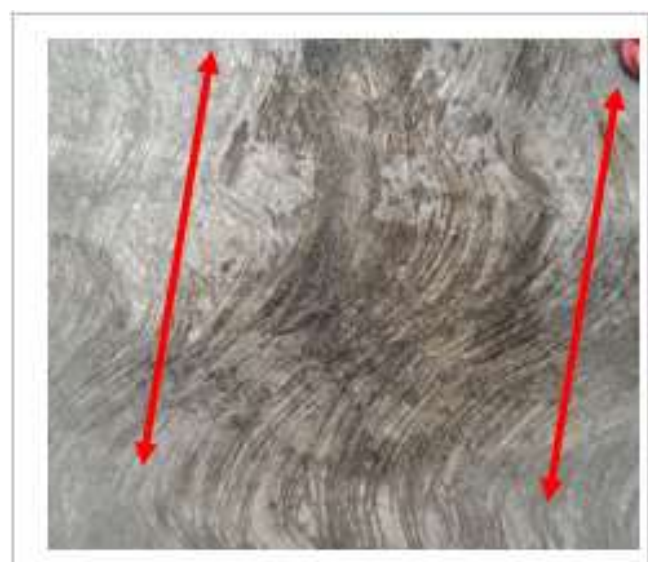

(a)

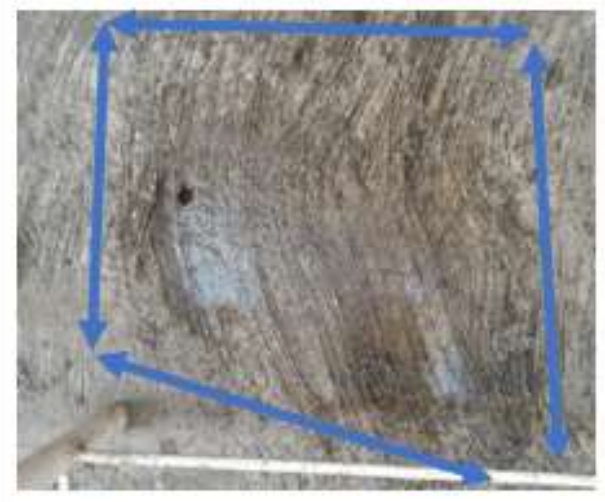

(c)

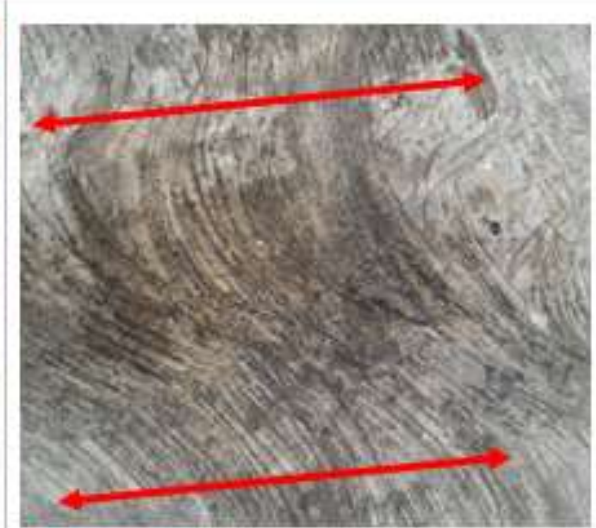

(b)

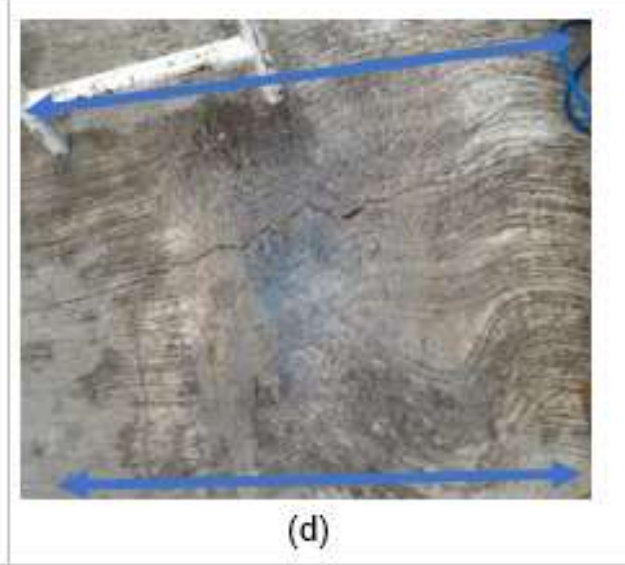

Gambar 7. Foto pengujian semprotan nozzle (a) $25 \%, 50 \%$ (b), $75 \%$ (c) dan $100 \%$, (d) ketinggian 2 meter.

Tabel 4. Pengujian nozzle water-pump

\begin{tabular}{cc}
\hline Percobaan & $\begin{array}{c}\text { Lama Waktu Dalam } \\
\text { Menyemprot (Detik) }\end{array}$ \\
\hline 1 & 34,33 \\
2 & 34,56 \\
3 & 35,58 \\
4 & 35,21 \\
5 & 36,36 \\
\hline Jumlah & 176,04 \\
\hline
\end{tabular}

Penyemprotan menggunakan quadcopter dilakukan untuk menguji water pump yang menyemprotkan cairan pada lantai dalam keadaan quadcopter terbang. Pengujian ini bertujuan untuk mengetahui lama waktu penyemprotan yang dilakukan quadcopter, sehingga dapat melakukan perbandingan hasil dari penyemprotan cairan pestisida dengan cara manual dan dengan cara menggunakan quadcopter. Pengujian ini dilakukan dengan ketinggian $3 \mathrm{~m}$ dan menggunakan persentase nozzle 75\%. Adapun hasil data yang diperoleh disajikan pada Tabel 4. 
Rata-rata lama waktu dalam pengujian ini adalah:

$$
\text { Rata-rata }=\frac{\Sigma}{n}
$$

$$
\Sigma=176,04, \mathrm{n}=5
$$

Maka rata-rata $=\frac{176,04}{5}=35,208$ detik

Dalam pengujian ini rata-rata penyemprotan yang dilakukan sebanyak 5 kali adalah 35,208 detik. Bila menyemprotkan cairan pestisida secara manual dengan luasan area $1000 \mathrm{~m}^{2}$, maka penyemprotan cairan pestisida dengan menggunakan quadcopter didapatkan lama waktu menyemprot yaitu 7041,6 detik $(1,956)$ dimana diperoleh dari :

a) Menyemprotkan cairan pestisida secara manual dengan luas area $1000 \mathrm{~m}^{2}$

$$
=2 \text { jam (7200 detik) }
$$

b) Menyemprotkan cairan pestisida menggunakan quadcopter dengan luas area $5 \mathrm{~m}^{2}$ $=35,208$ detik

c) Maka perbandingan skala menyemprotkan cairan pestisida secara manual dan dengan quadcopter adalah

$=$ Luas $1000 \mathrm{~m}^{2}:$ Luas $5 \mathrm{~m}^{2}$

$=200$

$=200: 1$

d) Lama waktu untuk menyemprotkan cairan pestisida pada area dengan luas $1000 \mathrm{~m}^{2}$ adalah:

$=35,208 \times 200$

$=7041,6$ detik

$=1,956 \mathrm{Jam}$

\section{Kesimpulan}

Berdasarkan hasil penelitian dan pengujian penyemprotan cairan pestisida menggunakan quadcopeter yang telah dilakukan, maka dapat disimpulkan, quadcopter telah dapat membawa alat semprot dan komponen tambahan lainnya dengan seimbang menggunakan motor brushless Sunnysky 3508-16 KV700kv dan propeller dengan ukuran 13x5,5-inch. Quadcopeter telah dapat menyemprotkan cairan pestisida pada area sawah menggunakan dua metode penerbangan yakni GPS-hold dan waypoint. Water-pump dapat diaktifkan ketika quadcopter terbang dengan menngunkan rangkain $\mathrm{RC}$ switch yang terhubung dengan remote control receiver. Penyemprotan pestisida menggunakan quadcopter mengahsilkan penyemprotan yang sempurna, apabila penyemprotan dilakukan dengan ketinggian $3 \mathrm{~m}$ dan dengan menggunakan persentase nozzle holder sebesar $75 \%$. Lama penyemprotan cairan pestisida menggunakan quadcopter pada area sawah seluas $1000 \mathrm{~m} 2$ adalah 1 jam lebih 15 menit. Penyemprotan tersebut lebih cepat dari penyemprotan menggunakan konvensional punggung dengan lama waktu penyemprotan 2 jam.

\section{Referensi}

[1] F. R. Abadi, "Penggunaan Quadcopter di Bidang Pertanian, Terobosan Tepat Guna dan Efisien untuk Pertanian Modern.", 2014. [Online]. Available: http://kaltim.litbang.pertanian.go.id/ind/index.php?option=com_content\&view=article\&id=566 :penggunaan-quadcopter-di-bidang-pertanian-terobosan-tepat-guna-dan-efisien-untukpertanian- modern-\&catid=26:lain\&Itemid=59. [Accessed: 16-Sep-2017].

[2] S. C. D. Sulistyoningrum, "Gangguan Kesehatan Akut Petani Pekerja Akibat Pestisida Di Desa Kedung Rejo Kecamatan Megaluh Kabupaten Jombang," p. 94, 2008.

[3] Gilang (2015), "Cara Menerbangkan Quadcopter bagi Pemula". Available at: https://www.gilangajip.com/cara-menerbangkan-quadcopter-pemula/ (Accessed: 3 November 2016).

[4] Guntara, I. (2013), "Pengertian Layanan Waypoint dalam Sistem GPS". Available at: http://www.guntara.com/2013/10/pengertian-layanan-waypoint-dalam.html (Accessed: 3 November 2015).

[5] Hamdani, C. N. (2013) 'Perancangan Autonomous Landing pada Quadcopter dengan Menggunakan Behavior-Based Intelligent Fuzzy Control', Jurnal Teknik POMITS, 2(2), pp. 63-68. 
[6] Perancangan dan Implementasi Sistem Pengaturan Optimal LQR untuk Menjaga Kestabilan Hover pada Quadcopter', Jurnal Teknik ITS, 1(1), pp. 7-13.

[7] Lema, R. A. N. (2016) 'Flight Controller Pada Sistem Quadcopter Menggunakan Sensor Imu (Inertial Measurement Unit) Berbasis Mikrokontroller Atmega 2560', Tugas Akhir, 116, p. 116.

[8] Multazam (2016) 'Pengaplikasian Autopilot Pada Pesawat Uav Sky King Untuk Misi Monitoring', p. 67.

[9] Ramadhan, B. (2015) 'Realisasi quadcopter yang dikendalikan dari pc dengan komunikasi data melalui frekuensi radio pada band frekuensi uhf (sisi penerima)', p. 78.

[10] Taufik, I. (2011) 'Pencemaran Pestisida pada Perairan Perikanan di Sukabumi- Jawa Barat', Media Akuakultur, 6(1), pp. 69-75.

[11] Akbar, S.A. dan Anton, Y (2016), "Prototipe Tabung Semprot Pupuk Cair Berbasis Wahana Quadcopter Bagi Lahan Tanaman Padi", ECOTIPE, 3(2), pp. 26-30 